\title{
Ecological Citizenship Through Education and Management
}

\author{
${ }^{1}$ Adhiarja Bintang \\ ${ }^{1}$ University of Indonesia, Kota Depok, Jawa Barat 16424, Indonesia. \\ 1bintangad998@gmail.com
}

\author{
Article Info \\ Journal of Journal of Enterprise and Business Intelligence (http://anapub.co.ke/journals/jebi/jebi.html) \\ Doi: https://doi.org/10.53759/5181/JEBI202101014 \\ Received 16 January 2021; Revised form 12 March 2021; Accepted 04 April 2021. \\ Available online 05 July 2021. \\ (C)2021 Published by AnaPub Publications.
}

\begin{abstract}
The dominance of the Indonesian population in 2018 for the productive age group (aged 15-64) reached 67.6\% of $265,000,000$ people, with $25.2 \%$ adolescents among the productive ages. Adolescence seek new ways to redefine themselves (identity processes) and to explore new ideas and challenges, so it is important to understand how they influence others and how they could have an impact on their families, communities, and the world. This understanding will encourage adolescents to become political actors to take action (WTTA) by influencing society on ecological citizenship, which concerns rights, entitlements, duties, obligations, and responsibilities to ensure that ecological footprints make a sustainable impact. Adolescents need community and social support to develop this ecological citizenship along with their own identity processing and coping with their life struggles. The idea of this paper is to offer food chemistry education as an alternative health and nutrition information so as to facilitate the ability of adolescents to achieve the appropriate development for ecological citizenship. This paper aims to discuss how food chemistry education develops Indonesian adolescents as the future generation who will manage the quality of the environment by becoming ecological citizens through their various life struggles. The discussion will be based on a literature review.
\end{abstract}

Keywords - Indonesian Adolescents; Ecological Citizenship; Adolescence; Food Chemistry Education; Sustainable Society.

\section{INTRODUCTION}

In [1] validated the Malthusian Theory on the Nigerian economy that population growth and food production can move proportionally in the long-run. In 2018, the Indonesian population was $265,000,000,67.6 \%$ of whom are in the productive age group (aged 15-64). Among the productive age group, 25.2\% are adolescent (aged 10-19). Adolescence is a predictable developmental stage of human capital investment [2] to support economic growth and achieve sustainable development simultanously. Investments into the development of human capital are defined as the stock of knowledge, skills, attitudes, health, and other personal characteristics that enable individuals to realise their full potential as productive and responsible members of society.

Adolescence continue to seek new ways to redefine themselves (identity processes) and to explore new ideas and challenges [3] , so it is important to understand how they will influence others and what impact they have on their families, communities, and society. This understanding will encourage adolescents to take action (WTTA) by influencing the society to move more towards ecological citizenship [4]. The identity processes of adolescents (commitment, in-depth exploration, and reconsideration of commitment) and political participation are linked [5]. This link is mediated by social responsibility, such as involvement in volunteer activities for the good of their community and playing the role in making the world a better place.

On the other hand, ecological citizenship obliges us to rethink the traditions of citizenship. The first virtue of ecological citizenship is justice, which aims to ensure a just distribution of ecological space. The second is care and compassion/sympathy for humans or non-human beings [6]. By this condition, adolescents need community and social support to develop ecological citizenship along with identity processing and coping with any life issues [7]. Crocetti, Jahromi, and Meeus [8] also found that educated adolescents showed more involvement in volunteer activities with a reported higher civic efficacy [9], and had stronger aspirations to contribute to their communities. Liska [10] stated that adolescents have specific health needs. The systems need to take into account their biological, emotional, and social development to support their attainment of a productive, healthy, and satisfying life.

To raise the willingness to take action for adolescents, society needs to prioritize actions to include health education, access to health services, immunization, nutrition, and psychological support. The idea of this paper is to offer food chemistry knowledge as an alternative health and nutrition education. Food chemistry education can facilitate the needs of adolescents to achieve their appropriate development into ecological citizenship. This paper aims 
to discuss how food chemistry education develops Indonesian adolescents for improving future generations by becoming ecological citizens. The discussion involves a literature review.

\section{Ecological Citizenship}

Ecological citizenship concerns rights, entitlements, duties, obligations, and responsibilities to ensure that ecological footprints make a sustainable impact. Ecological footprints are defined as the impact of the production and reproduction of individuals' and collectives' daily lives on strangers, near and far, to whom the obligations of ecological citizenship are owed. Ecological citizenship transforms the community of citizenship, not just the moral community. Dobson stated that ecological citizens are most likely to be created through lived experiences characterized by exercising ecologically related responsibilities, nationally, internationally, and intergenerationally, which remains rooted in justice in public and private spheres. [11] argued that ecological citizenship is too closely associated with market-based mechanisms for pro-environmental behavior change through emphasizing its responsibilities and virtue, which is sometimes in opposition to market logistics. The development of ecological citizenship needs to focus on the processes and political arrangements that produce pro-environmental behaviors, and explicit engagement with the roles, capacities, priorities, and powers of the diverse actors who are involved in these processes.

\section{Engaging adolescents to become ecological citizens}

Engaging adolescents to become ecological citizens can be done by promoting civic identity such as volunteering in communities. This requires parental support and communication to ensure a link to adolescent moral reasoning about community service and the development of civic identity. Adolescent political involvement is influenced by education and behavioral family-level variations. Raising environmental awareness can engage adolescents to participate in ecological issues, starting from asessing their knowledge and describe their willingness to pay and take action. [12] stated that a visual display of meaningful, interconnected concepts that represent an individual's unique, lived experience, and knowledge of an ecological topic can drive adolescent conceptual mapping.

Ecological citizenship can initially be developed and achieved in school through perceptions of sustainability issues, which is shaped by aspects of ecological citizenship and political solidarity. This is also informed by the local context, so that teachers move from a more environmentally-centered conception of sustainability to a definition that included the other pillars of economic and socio-political sustainability. Education about sustainability and the environment should drive adolescents to be ecologically aware by seeing themselves as the incarnation of the land and having uniqueness and aesthetics for others to admire, understand, and emulate a sustainable world. Education for sustainability should provide the psychologies of learning to effect the sensitivities, dispositions, and awareness reach into the soul of the adolescents to impact their affects, emotions, and desires. In [14] stated that the citizen needs to be made continually aware and the school can be the central site for making a citizen who inhabits the spaces of participation. In school, a person can speak about social and educational theories that can develop modes freedom, empowerment, participation, and collaboration to foster equitable and just societies.

\section{Sustainable society toward ecological citizenship}

The level of participation in sustainable society management toward ecological citizenship for adolescents depends on decision-making power, labor contribution, cost bearing, and the number of community members involved. Adolescents should be given full responsibility for and control over their own future. Schools can be the central site to develop their decision-making power together with teachers, parents, and local culture as the stimulation to build a collective action concept suitable to normal adolescent interests and needs. The financial grants that support developing a sustainable society should be focused on empowering adolescents with technology, education, practical knowledge and skills, so that they may develop new perspectives on their lives and what they can do .

Building up culture in adolescents can be embedded in volunteer work. Adolescents as active citizens in their community and school interest can get involved in volunteer activities and earn additional economic incentives, which brings additional attractiveness to participate. At the point when youths share a feeling of personality, hold comparative qualities, trust one another, and equally get things done for one another, it will be simpler to accomplish a supportable society toward environmental citizenship. [13] stated that sustainable society participation toward ecological citizenship needs openness to global science collaborations as an alternative growing sector of the global distributed knowledge and learning systems that encourage innovation-smart processes and leverage cross-border international collaborations. [15] argued that the collaboration of global science can be focused on building common causes to implement more sustainable consumption.

When Indonesian adolescents agree to follow the guidelines of consuming nutritious, balanced, and diverse food plus active in their everyday life, then Indonesia will be able to achieve food security simultaneously to preserve the 
ecosystem services to achieve biodiversity by at least $25 \%$. [16] stated that food security and biodiversity can be achieved simultaneously in Fig 1.

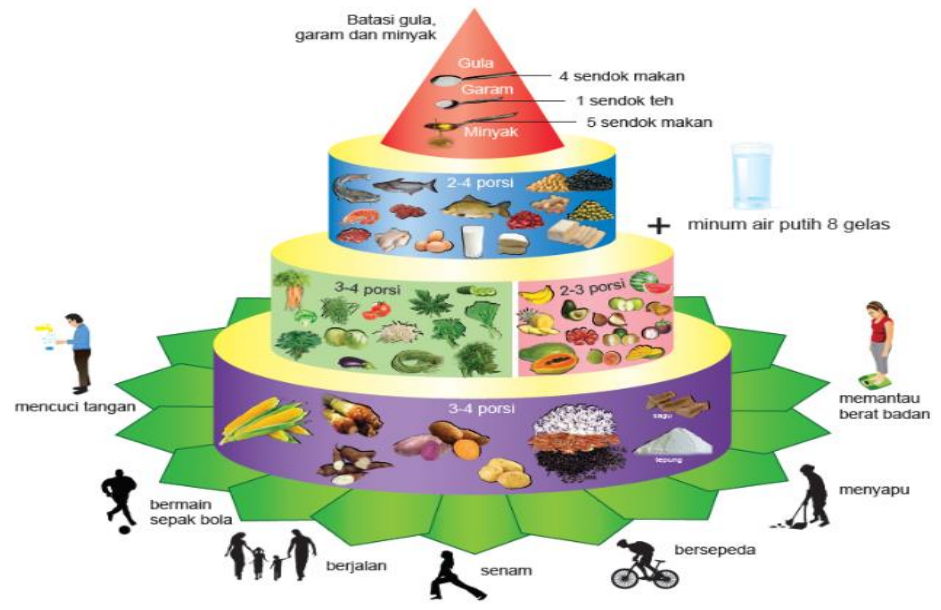

Fig 1. The guidelines of nutritious, diverse, and balanced (NUDIBA) plus active to achieve a healthy community

Food chemistry education based on Indonesian culture

The Indonesian culture in this review is mostly discussed in terms of Lamoureux's study: Indonesia: A worldwide investigations handbook. Indonesia is the biggest archipelago on the planet with more than 17,000 islands, a landmass of around 760,000 square miles, and the joined coastline of the apparent multitude of Indonesian islands is roughly 33,900 miles. The Indonesian islands are situated above and underneath the equator; some are arranged straightforwardly on it. The islands of Indonesia are isolated into four areas: (1) the Greater Sunda Islands which are Sumatera, Java, Bali, Kalimantan, and Sulawesi; (2) the Lesser Sunda Islands, which are Lombok, Sumbawa, Sumba, Flores, Komodo, and Timor; (3) various littler islands, which are Halmahera, Ternate, Tidore,Seram, and Ambon including Maluku; (4) West Papua. The nation stretches out from the Indian Ocean into the South China Sea and on to the Pacific Ocean. Numerous islands verge on or are encircled by littler waterways, for example, the Strait of Malacca, the Java Sea, Banda Sea, Celebes Sea, and the Timor Sea.

Indonesia's populace is made out of numerous ethnic gatherings. The biggest of these are the Javanese, Sundanese, Batak, Balinese Acehnese, Minangkabau, Dani, Dayak, Punun, and Bugis. The principle religions are Islam, Christian (Protestant and Catholic), Hindu, Buddhist, Tao, and Indigenous religions. More than 250 unique dialects and tongues are spoken, having a place with the Austronesian language family, however a few sources put the numbers as high as 600. The proverb is Unity in Diversity and the public language is Bahasa Indonesian. Indonesian dishes are produced using privately developed and imported nourishments from around the globe, for example, India, South America, Europe, and China. Soybeans are utilized widely in Indonesian cooking, and their high dietary benefit is a fundamental explanation behind the great wellbeing of numerous less fortunate Indonesians. The two well known dishes produced using soybeans are tahu (tofu) and tempe. Ketcap (soy sauce), as a flavor enhancer, is additionally produced using soybeans and used to season numerous meat and vegetable dishes.

Harmayani, Santoso, and Gardjito stated that Indonesia has many traditional dishes made from fermented products - vegetables such as tofu, tempe, ketcap, gathot, and animal products such as bekasan, terasi/belacan (shrimp paste). Furthermore, Indonesia also has many traditional dishes based on ethnic diversity from regions of Indonesia such as Lontong Medan, Soto Betawi, Papeda, etc. Food chemistry education at school can be the central focus for developing Indonesian traditional dishes.

The main study of food chemistry education can be improved to develop rempah-rempah, which is an Indonesian traditional food flavor, toward modern functional food and herbal medicine, since these rempah-rempah are endemic to the Nusantara regions. To support food chemistry education to become the central study at school, Sofia, Permanasari, Sholihin, and Supriyanti, argued that the Indonesian Ministry of Education must ensure that the teacher education institution to fulfills the competency standards of chemistry education candidates, mainly with regards to competency standards related to food chemistry. But, this literature review proposes that food chemistry education at school must be based on adolescent learning outcomes to achieve the normal adolescents, as well as to improve their willingness to participate in healthy eating habits towards a sustainable society.

Food chemistry education towards sustainable society 
Lamoureux's stated that the green revolution in around 1970-1980 had impacted food diversity in Indonesia. Before this green revolution, Indonesia haf four kinds of carbohydrates rice, cassava, corn, and sago but rice is the main carbohydrate in most regions of Indonesia, including West Papua. Many scientists are concerned about the impact of the green revolution on biodiversity, especially food diversity which will affect food security in Indonesia. Based on the phenomena of food diversity in Indonesia after the green revolution, the Indonesian Ministry of Health has been promoting the consumption of nutritious, balanced, and diverse foods to develop food security, as well as achieve good health and well-being.

Unfortunately, adolescents, especially those who live in cities, have poorer knowledge about staple food diversity. Their preferences for staple food, basically rely on its taste and appearance.

Telfer accepted that the job of food and eating brought up numerous focal issues in moral way of thinking, for example the degree of our commitment to the destitute, the chance of obligations to oneself, and the spot of exceptional commitments in profound quality. Now and again, individuals found that eating can be a recreation movement to look for joy and exercise decision, yet it I likewise for endurance. This is one condition that clarifies the most broad obligation to others concerning food: to be fit to play out one's obligations to other people. Great wellbeing empowers one to play out one's obligations to oneself, which comprises of the activity of independence and the advancement of self-improvement in the decision and quest for standards remembering beliefs for food and eating, such that bolsters the planet's food gracefully. Strikingly, Heaven portrayed that young people's idea of being solid is satisfying one's latent capacity, having the option to work genuinely, intellectually, and socially, just as encountering positive enthusiastic states.

This concept is linear with the result of Simanjuntak's research that adolescents make a list of staple food preferences based on taste and appearance. Food chemistry education in schools must facilitate adolescents' experiences about food and eating to engage them in participating in healthy eating habits and to fulfil their duties in a sustainable society by a comprehensive knowledge of accessing their food and eating. As Salonen and Åhlberg said, sustainable societies is where diverse life can flourish now and in the future. Usually, the transformation starts from a change in personal behavior and leads to policy changes, thus food chemistry education should improve adolescent awareness by facilitating their willingness to participate and take action in promoting a healthy lifestyle, recycling, healthier and cleaner food consumption such as organic food, water-saving, civil society maintainance, favouring ecolabelled products and services renewable energy resources.

Food chemistry education develops adolescents' self-determination motivation as sustainable society

The Self-determination theory (SDT) by Ryan and Deci discusses motivation, development, and wellness as the basic psychological needs. For adolescents, parents' play a big role in SDT's approach through their responsiveness to developing adolescents' basic psychological needs. The approach begins with the assumption of inherent growth processes, including intrinsic motivation, relatedness, internalization, and integration. SDT specifies three critical dimensions of parenting autonomy support, structure, and involvement which influence adolescents' internalization and basic needs satisfaction. Sensitivity by parents' responsiveness and autonomy-supportive are the basis for secure relatedness. Adolescents can learn and grow by satisfying their basic psychological needs when their parents are involved and autonomy-supportive while providing structure. Parental support for adolescent basic needs leads to more internalization and autonomous functioning, which in turn is related to greater well-being. Adolescents are more likely to internalize their guidance and values when they are securely attached to parents, but those who feel unrelated and detached from parents will be more oriented toward internalizing the values of peers or extra familial subcultures to which they feel (or wish to feel) attached.

Ryan and Deci described the key elements of parenting dimensions for adolescents, which are taking the adolescents' perspective, offering meaningful choices, encouraging and supporting initiative and voice, minimizing controlling language, and providing meaningful rationales for required or requested behaviors. Parents must organize the adolescents' environment to support competence (scaffolding), focus on mastery rather than performance goals, provide guidelines and effectance-relevant information, rich feedback that is informational rather than evaluative or controlling, explain contingencies and sources of control, and set limits in a non-controlling way. The key elements of parental involvement are devoting time, investing attention and resources, being caring and supportive, and showing warmth and concern.

Obviously, meaningful information has a major role in adolescents' psychological needs by developing an intrinsic motivation to learn and assimilate, which is why schools should capitalize on students' intrinsic motivation instead of emphasizing extrinsic motivators by grades, awards, and social comparisons attached to external pressures, controls, and punishment. Intrinsic motivation has significance for student engagement and cognitive growth, and the conditions that support it in classrooms, which leads to autonomous motivation such as the internalization of values for learning and academic achievement. 
Ryan and Deci suggest that schools create educational environments to boost students' intellectual and socialemotional characteristics. If the intellectual and social-emotional factors increase enjoyment along the learning process, then adolescents will be able to reach a good learning achievement. In line with Li's findings, Ivanova and Ivanova described an adolescent learning style that needs to be facilitated during the learning process; i.e. making learning fun and more relevant to them and their world, so they can receive information quickly, with less step-bystep instruction, more random access, hyperlinked, just-in-time learning experiences, less text and more pictures, sounds and video wherever possible, more opportunities for multitasking, networking and interactivity.

Furthermore, a school must provide autonomy-supportive behaviors for increased self-determined motivation. The behaviors include offering meaningful choices and allowing adolescents to have a say in the decision-making process, minimize pressure and control, and acknowledge the feelings of others. Autonomy-supportive behaviors at school, especially, are executed by teachers through implementing autonomy-supportive teaching strategies that foster more autonomous forms of motivation in students and a higher quality of engagement, performance, and the positive experiences associated with it. However, teachers also need positive support for implementing autonomy-supportive teaching strategies. The food chemistry education in schools proposed in this paper is a problem-based and projectbased learning model to increase adolescents' higher order thinking skills and to develop their willingness to take action as a part of a sustainable society toward ecological citizenship. Food chemistry problem-based and projectbased learning models will encourage adolescents to explore their capacity to involve parents, teachers, and peers along the food chemistry learning process.

\section{DISCUSSION}

This literature review uses the concept of ecological citizenship by Dobson, which states that ecological citizenship concerns rights, entitlements, duties, obligations, and responsibilities to ensure that ecological footprints make a sustainable impact. Ecological citizens are most likely to be created through lived experience and are characterized as exercising ecologically related responsibilities, nationally, internationally, and intergenerationally, which remains rooted in justice, in both the public and private sphere.

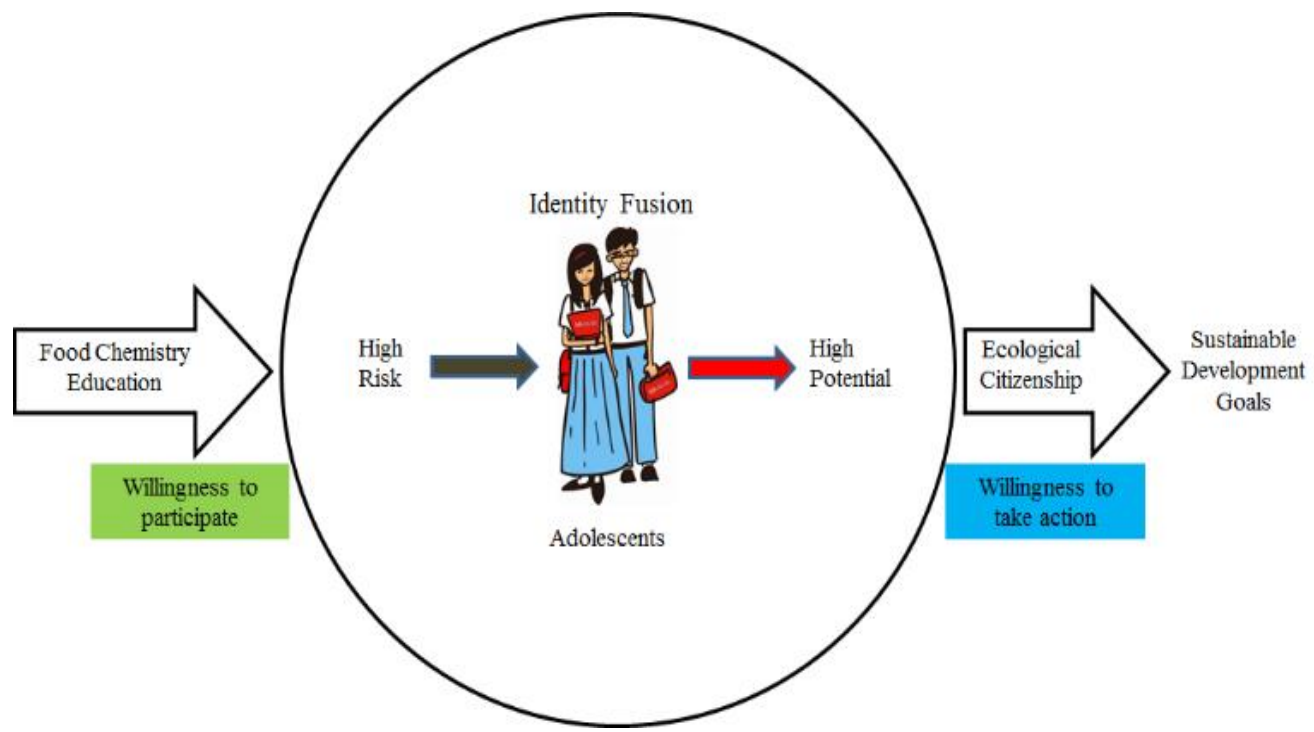

Fig 2. The illustration of the connection between ecological citizenship, adolescents, and food chemistry education

Engaging adolescents to be ecological citizens is to help them achieve normal development through healthy eating habits participation. Adolescents' participation can be facilitated by the food chemistry education processes in schools together with their peers, teachers, as well as parents, to encourage them to make a good relationship, which is said by Scott, Duell, and Steinberg, affects adolescents' emotional maturity and allow them to cope with problems or conflicts. To achieve adolescents' normal development, food chemistry education should optimize the moral by focusing on their interest, especially related to the benefit of healthy eating habits. Food chemistry education can facilitate adolescents' experiences about food and eating to increase their interest in reading relevant and empowering books and information to enhance their comprehensive knowledge, improve their analytical and critical thinking, as well as to find out their true interests and talents for fulfilling their duties in a sustainable society, which is where diverse life can 
flourish now and in the future. As Ryan and Deci suggestion, food chemistry education in schools should create educational environments as a positive determinant to adolescents.

The positive determinant will boost adolescents' intellectual and social-emotional characteristics that increase enjoyment along the learning process which supports adolescents learn in their style so they can reach a good learning achievement. If adolescents feel enjoyment along with the chemistry learning and also get a good learning achievement, they will be more eager to participate in healthy eating habits then lead them to be more aware of food security and encourage them to take action on environmental preservation. By this condition, the school actively develop sustainability shaped the student teachers' perception by aspects of ecological citizenship and political solidarity as the gateway to reach sustainable development goals. The connection between ecological citizenship, food chemistry education and adolescents can be seen in Figure 2.

\section{CONCLUSION}

To develop Indonesian adolescents' become ecological citizens, food chemistry education can embed as a chemistry learning process at school. The embedding by providing an integrated learning module to facilitate the adolescents' chemistry learning style, and as well as to reduce the students' chemistry anxiety. Integrated chemistry learning module should involve students' knowledge, feelings, hope, and experience of food and eating, so they can achieve actively their development tasks as adolescence by healthy eating habits, and individually, improve their quality of life as Indonesian human resources.

\section{References}

[1]. J. W. Chesser, "Human Resource Management in a Union Environment," Human Resource Management in a Hospitality Environment, pp. 217-227, Mar. 2017.

[2]. P. MURPHY, "Environment and site management," The Business of Resort Management, pp. 207-245, 2008.

[3]. P. Smith Ring, "The Environment and Strategic Management," Handbook of Strategic Management, pp. 89-122, May 2000.

[4]. M.-V. MISSING-VALUE, "Advertising Management Environment," Cases in Advertising Management, pp. 85-92.

[5]. R. McCrie, "Security Operations in the Management Environment," Security Operations Management, pp. 3-35, 2016.

[6]. J. Kennedy, "The changing collection management environment," Collection Management, pp. 1-10, 2006.

[7]. B. E. Gup, "Bank Capital Regulation and Enterprise Risk Management," Enterprise Risk Management, pp. 337-350, Dec. 2011.

[8]. B. C. Branson, "The Role of the Board of Directors and Senior Management in Enterprise Risk Management," Enterprise Risk Management, pp. 51-67, Dec. 2011.

[9]. P. Sweeting, “An Introduction to Enterprise Risk Management," Financial Enterprise Risk Management, pp. 1-10.

[10]. P. Sweeting, “An Introduction to Enterprise Risk Management,” Financial Enterprise Risk Management, pp. 1-10.

[11]. D. Spiegelberg, "Enterprise Marketing Management (EMM)," Enterprise Marketing Management, pp. 19-45, Dec. 2012.

[12]. A. KUCUK YILMAZ, “Airport Enterprise Risk Management,” Enterprise Risk Management, vol. 1, no. 1, Mar. 2009.

[13]. R. Nason, "Credit Risk Management," Enterprise Risk Management, pp. 261-278, Dec. 2011.

[14]. V. Kale, "Enterprise Process Management Systems Applications," Enterprise Process Management Systems, pp. 327-398, Oct. 2018.

[15]. S. R. Iyer, D. A. Rogers, and B. J. Simkins, "Academic Research on Enterprise Risk Management," Enterprise Risk Management, pp. 419-439, Dec. 2011.

[16]. D. A. Rogers, "Managing Financial Risk and Its Interaction with Enterprise Risk Management," Enterprise Risk Management, pp. 321335, Dec. 2011. 